\title{
Improved Indirect Field Oriented Control based Three Phase Induction Motor
}

\author{
Dr.RaaedFaleh Hassan ${ }^{1}$, Mahmood Sawadi Rahi ${ }^{2}$ \\ Electrical Engineering Technical College, Iraq ${ }^{1,2}$
}

\begin{abstract}
In recent years a number of studies have been carried out in relation to improvements in control methodologies for induction motors, and due to the great progress achieved in power electronics and microcontrollers, it has been possible to implement advanced Control for this type of electric motors. The purpose of this paper is to achieve the implementation of an advanced control technique, such as vector control for induction motors. Specifically, the methodology is Indirect Field Oriented Control (IFOC) based on the space vector pulse width modulation necessary for the control of the inverter that feeds the motor. The main characteristic of the vector control is that it allows direct control of the stator current according to the desired requirements and improving its efficiency. In this paper project the analysis and the implementation of indirect field oriented control (IFOC) for a three-phase induction motor. This control algorithm makes use of Two PI controllers are available for the currents, and another PI controller for the speed, which together make motor control possible. The main objective of the control is to follow a speed reference and maintain it in spite of the presence of disturbances. In addition, relationship between the reference speed and the reference current, in order to achieve control over a wider range of speeds. The software used to perform the simulations in this paper is MATLAB/ Simulink are used to perform the simulations of the mathematical model and the control algorithm .the components used are presented and the results obtained which shows the behaviour of the currents at different speed levels are high response.
\end{abstract}

Keywords:indirect field oriented control,PI controllers, space vector pulse width modulation.

\section{INTRODUCTION}

Currently, three-phase induction motors are the preferred type of motor in the industry, this is due to the benefits they present to other types of electrical motors, such as their low cost, robust structure, almost no maintenance need and High ratio of their power with respect to their size. Despite all the benefits they present, their main disadvantage is the difficulty in controlling them. For many years these machines have been connected directly to a voltage line operating at a constant speed, and more recently they have been controlled under scalar type schemes, based on the voltage / frequency (V / f) ratio to reach different operating points, But this method has the disadvantage of having an undesired dynamic behaviour due to effects of magnetic saturation and changes in the electrical parameters of the motor (such as the electrical resistance of its windings) due to temperature[1-2]. The control of the three-phase induction motor is a difficult and complex problem due to several reasons. First, the system has a non-linear behaviour. Second, it is multivariate and its state variables cannot be measured directly, so estimates are usually made based on the mathematical model. Finally, some of its parameters (mainly rotor resistance) can vary during the operation of the machine due to situations that may arise (environmental factors such as temperature, sudden increases in load, etc.). The industry today has as one of its main objectives the reduction of operating costs of its processes, therefore the classic techniques of motor control are ruled out by the low energy efficiency they
Offer, then it becomes necessary to have techniques of advanced control that optimize its operation and therefore its performance, for that reason in recent year's research has been promoted around the control of this electric machine [3]. One of the advanced techniques of electric motor Control is the Field Oriented Control (FOC), which considers its mathematical equations and therefore achieves

A better control of the torque or speed dynamics according to the specific methodology Used. The FOC control requires a higher calculation power than a V / f control, which can be overcome when using digital signal processors or DSP [4]. The work is divided into five parts: It begins with vector control that include mathematical modelling of the induction motor, the transformations necessary to implement the control and the indirect fieldoriented control is then described.

Later, the Space Vector Pulse Width Modulation, necessary for the control of the inverter that feeds the motor .In section four, the MATLAB / Simulink are used to perform the simulations of the mathematical model and the control algorithm. Finally the results obtained from the IFOC control is described, the components used are presented and the results obtained are shown. At the end of this project it is concluded that. The implementation of the controller was performed successfully; a speed reference was monitored, as well as the control in the presence of disturbances. 


\section{VECTOR CONTROL METHODS}

Within the vector control can be differentiated two methods that can be achieved depending on the way in which the orientation of the magnetic flux of the rotor is determined: direct and indirect. In both methods it is necessary to have a position sensor and rotor speed, but it is possible to do without using the technique called sensorless. The General block diagram for FOC.

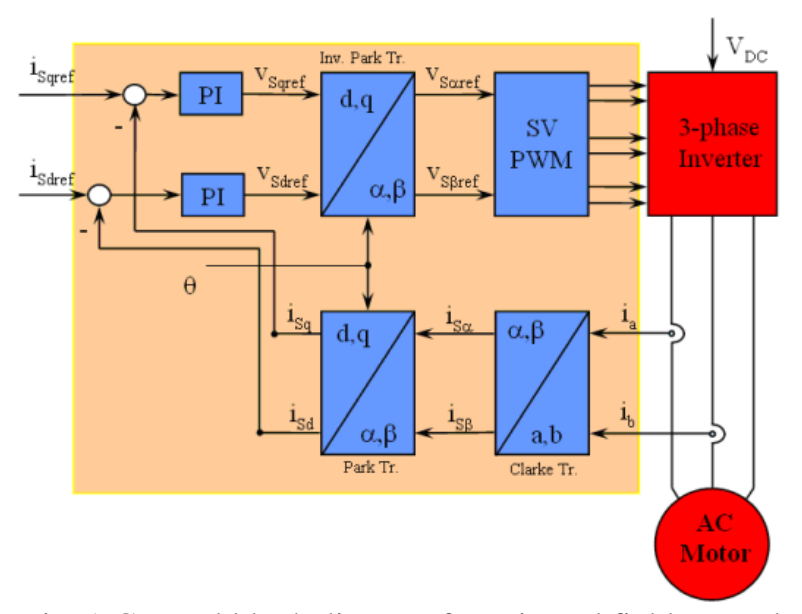

Fig. 1:General block diagram for oriented field control.

The indirect field-oriented control was developed by Hasse. In comparison to the DFOC, in the IFOC control no sensors or modifications are required in the motor, since the rotor flux is estimated based on the mathematical model and also based on the measurements of the motor currents [5]. Industrially this is the preferred FOC control method due to the lower cost involved with the DFOC [6]. The scheme that will be followed in this work to carry out the implementation of the IFOC control is shown in Fig 2:

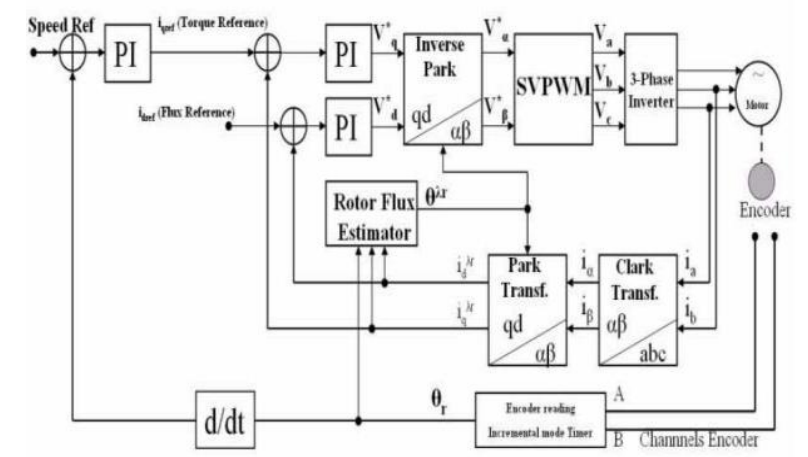

Fig. 2:IFOC control scheme.

As can be seen in the diagram shown in fig (2), the control to be implemented will be a speed control. A current value will be set and the speed reference will be varied. The control is performed by three PI controllers (one of speed and two of currents). The output of the control algorithm are six PWM signals that control the motor power through a three-phase inverter. The control loops are closed by reading the rotor speed and the motor feed currents. To develop the IFOC control equations, it is necessary to rewrite the induction motor equations. In these new expressions will apply the conditions required by this method of control and thus will be deduced the equations that will finally be implemented.

To arrive at the equations that define the indirect control of oriented field, it is necessary that the following conditions are met:

The coordinate system must rotate at the same speed and next to the rotor field in such a way that:

$\omega=\omega_{\mathrm{mr}}(1)$

The vector of the rotor flux must match the direction of the d-axis, then:

$\Psi_{\mathrm{r}}^{\prime}=\Psi_{\mathrm{dr}}^{\prime}(2)$

$\Psi_{\mathrm{qr}}=0(3)$

$\mathrm{U}_{\mathrm{dqs}}=\mathrm{R}_{\mathrm{s}} \mathrm{I}_{\mathrm{dqs}}+\frac{\mathrm{d} \Psi_{\mathrm{dqs}}}{\mathrm{dt}}+\omega \Psi_{\mathrm{qds}}(4)$

$\mathrm{U}_{\mathrm{dqr}}^{\prime}=\mathrm{R}_{\mathrm{r}}^{\prime} \mathrm{I}_{\mathrm{dqr}}+\frac{\mathrm{d}^{\prime} \mathrm{dqr}}{\mathrm{dt}}+(\omega-\omega \mathrm{r}) \Psi_{\mathrm{qdr}}^{\prime}(5)$

Now, rewriting equations (4) and (5) considering a real and imaginary coordinate system of axes:

$\mathrm{U}_{\mathrm{dqs}}=\mathrm{R}_{\mathrm{s}} \cdot \mathrm{I}_{\mathrm{dqs}}+\frac{\mathrm{d} \Psi_{\mathrm{dqs}}}{\mathrm{dt}}+\mathrm{j} \omega \Psi_{\mathrm{qds}}(6)$

$0=\mathrm{R}_{\mathrm{r}}^{\prime} \mathrm{I}_{\mathrm{dqr}}^{\prime}+\frac{\mathrm{d}_{\mathrm{dqr}}}{\mathrm{dt}}+\mathrm{j}(\omega-\omega \mathrm{r}) \quad \Psi_{\mathrm{qdr}}^{\prime}(7)$

In addition, by writing the rotor and stator fluxes as a function of inductances, we have:

$\Psi_{\mathrm{qds}}=\mathrm{L}_{\mathrm{s}} \cdot \mathrm{I}_{\mathrm{dqs}}+\mathrm{L}_{\mathrm{m}} \cdot \mathrm{I}_{\mathrm{dqr}}^{\prime}(8)$

$\Psi_{\mathrm{qdr}}^{\prime}=\mathrm{L}_{\mathrm{r}}^{\prime} \cdot \mathrm{I}_{\mathrm{dqr}}^{\prime}+\mathrm{L}_{\mathrm{m}} \cdot \mathrm{I}_{\mathrm{dqs}}(9)$

From equations (8) and (9) we arrive at:

$I_{d q s}=\frac{1}{\sigma L_{s}} \Psi_{q d s}-\frac{L_{m}}{\sigma L_{r}^{\prime} L_{s}} \Psi^{\prime}{ }_{q d r}(10)$

$\mathrm{I}_{\mathrm{dqr}}^{\prime}=\frac{\mathrm{L}_{\mathrm{m}}}{\sigma \mathrm{L}_{\mathrm{r}}^{\prime} \mathrm{L}_{\mathrm{s}}} \Psi_{\mathrm{qds}}-\frac{1}{\sigma \mathrm{L}_{\mathrm{s}}} \Psi_{\mathrm{qdr}}^{\prime}(11)$

Now, rearranging equation (10) we have:

$\Psi_{\mathrm{qds}}=\sigma \mathrm{L}_{\mathrm{s}} \cdot \mathrm{I}_{\mathrm{dqs}}+\frac{\mathrm{L}_{\mathrm{m}}}{\mathrm{L}_{\mathrm{r}}^{\prime}} \Psi_{\mathrm{qdr}}^{\prime}{ }^{\prime}(12)$

And in the same way reordering the equation (11) we have to:

$\mathrm{I}_{\mathrm{dqr}}^{\prime}=\frac{1}{\mathrm{~L}_{\mathrm{r}}^{\prime}} \Psi_{\mathrm{qdr}}^{\prime}-\frac{\mathrm{L}_{\mathrm{m}}}{\mathrm{L}_{\mathrm{r}}^{\prime}} \mathrm{I}_{\mathrm{dqs}}(13)$

Replacing (12) in (4):

$\mathrm{U}_{\mathrm{dqs}}=\mathrm{R}_{\mathrm{s}} \cdot \mathrm{I}_{\mathrm{dqs}}+\sigma \mathrm{L}_{\mathrm{s}} \frac{\mathrm{dI}_{\mathrm{dqs}}}{\mathrm{dt}}+\frac{\mathrm{L}_{\mathrm{m}}}{\mathrm{L}_{\mathrm{r}}^{\prime}} \frac{\mathrm{d}_{\Psi_{\mathrm{d}}^{\prime} \mathrm{dr}}}{\mathrm{dt}}+\mathrm{j} \omega \sigma \mathrm{L}_{\mathrm{s}} \mathrm{I}_{\mathrm{dqs}}+$ $\mathrm{j} \omega \frac{\mathrm{L}_{\mathrm{m}}}{\mathrm{L}_{\mathrm{r}}^{\prime}} \Psi_{\mathrm{qdr}}^{\prime}(14)$

And replacing (11) in (6):

$$
\begin{gathered}
0=R_{r}^{\prime}\left(-\frac{L_{m}}{L_{r}^{\prime}}\right) \cdot I_{d q s}+\frac{R_{r}^{\prime}}{L_{r}^{\prime}} \Psi_{q d r}^{\prime}+\frac{d_{\Psi^{\prime}}{ }_{d q r}}{d t}+j(\omega \\
\left.-\omega_{r}\right) \Psi_{q d r}^{\prime}
\end{gathered}
$$


Equations (14) and (15) represent the induction motor, and are written in such a way as to make it easier to see and apply the considerations necessary for IFOC control.

$\Psi_{\mathrm{r}}^{\prime}=\Psi_{\mathrm{dr}}^{\prime}=\mathrm{L}_{\mathrm{m}} \mathrm{i}_{\mathrm{mr}}(16)$

And pouring $i \mathrm{mr}$ :

$i_{m r}=\frac{1}{L_{m}} \Psi_{d r}^{\prime}(17)$

By operating, grouping terms and defining the stator and rotor time constant as:

$\frac{L_{s}}{R_{s}}=T_{s}(18)$

$\frac{L_{r}}{R_{r}}=T_{r}(19)$

In addition, the equations of torque, angular velocity and flux in the rotor can be written as follows:

$T_{e}=\frac{3}{4} \frac{L_{m}}{L_{r}^{\prime}} P\left(\Psi_{d r}^{\prime} \cdot I_{q s}\right)(20)$

$\omega_{m r}-\omega_{r}=\frac{i_{q s}}{T_{r} \Psi_{d r}^{\prime}}(21)$

$\omega_{s l}=\omega_{m r}-\omega_{r}=\frac{i_{q s}}{T_{r} \Psi_{d r}^{\prime}}(22)$

$\omega_{m r}=\omega_{s l}+\omega_{r}=\frac{i_{q s}}{T_{r} \Psi_{d r}^{\prime}}+\omega_{r}(23)$

$\Psi_{d r}^{\prime}=\int\left(i_{d s}-i_{m r}\right) \frac{1}{T_{r}} L_{m}(24)$

Where's,

Udqs: Vector Stator voltages in the reference frame

$R s$ : stator resistance.

Idqs: Vector stator currents in the reference frame.

$\omega:$ Arbitrary velocity [ $\mathrm{rad} / \mathrm{s}]$.

$\Psi d q s$ : Vector of stator coupling fluxes.

U'dqr: Vector rotor voltages in the reference frame referred to the stator.

$R ' r$ : rotor resistance referred to the stator.

Idqs: Vector stator currents in thereference frame.

I'dqr: Vector rotor currents in the reference frame referred to the stator.

$\omega r$ : Electric angular speed of the rotor $[\mathrm{rad} / \mathrm{s}]$.

$\Psi$ 'dqr: Vector of rotor coupling fluxes referred to the stator.

$\sigma:$ coefficient

$P$ : Number of poles.

Te: Electromotive torque $[\mathrm{Nm}]$.

Ids: Current of the stator in the axis d [A].

Iqs: Current of the stator on the axis $q[\mathrm{~A}]$.

I'dr: Current of the rotor in the direct axis referred to the stator [A].

I'qr: Current of the rotor in the quadrature axis referred to the stator $[\mathrm{A}]$.

$\Psi d s$ : Magnetic flux of the stator in the d-axis [Wb].

$\Psi$ 'qr: Magnetic flux of the stator on the axis q [Wb].

$\Psi^{\prime} d r$ : Magnetic flux of the rotor in the axis d referred to the stator [Wb].

I'qr: Magnetic flux of the rotor in the axis q referred to the stator $[\mathrm{Wb}]$.
With the equations presented in this section the model of the induction motor in oriented field is realized, and also the IFOC control is developed. The corresponding simulations are presented in the next section.

\section{III.SPACE VECTOR PULSE WIDTH MODULATION (SVPWM)}

In the IFOC control scheme presented in Fig (2), a block called SVPWM can be observed, the function of this block is to determine based on the reference voltage levels, a series of pulses with variable frequency (PWM), which will be The command signals for the IGBT transistors present in the inverter that will be used to power the induction motor [7].To explain the SVPWM modulation principle it is necessary to give a brief description of the Voltage Source Inverter (VSI), shown in Fig (3).

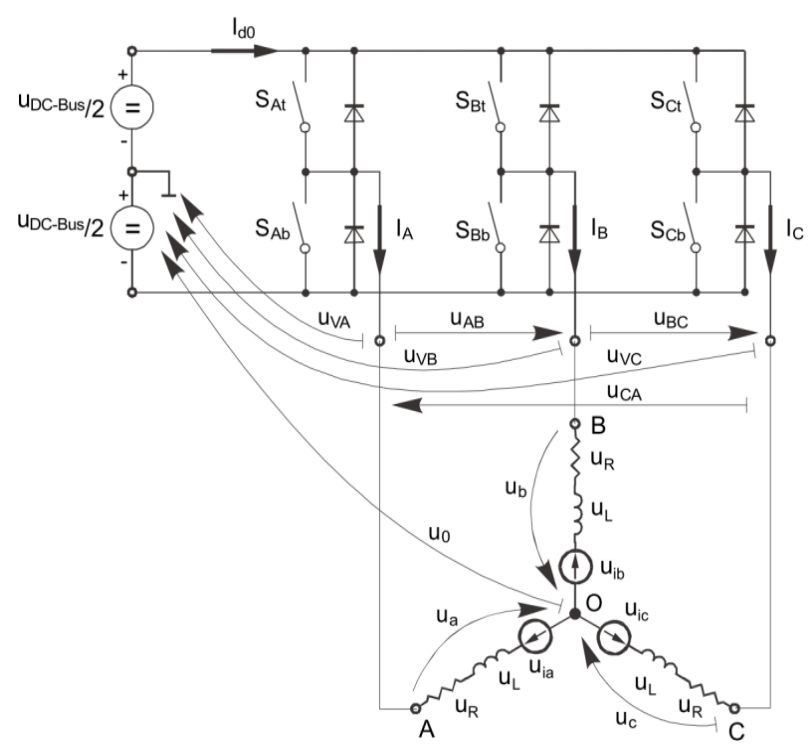

Fig. 3:Two levels inverter.

The inverter shown has a bridge topology with three branches (corresponding to the phases), and each branch is composed of two power switches and two anti-return diodes, this ensures that the power flow goes in only one direction: From the source towards the load, and not in reverse. The denomination of each switch will be as shown in the previous figure(3), where the first branch has two switches called SAt (upper switch) and SAb (lower switch), this designation is repeated for the remaining branches. In addition, it will be designated with a "1" when a top switch is active, and with a "0" when a lower switch is active. When using a two-level inverter (as shown in Fig 3), you can obtain eight different switching states of your switches, which you get by relating the levels and the number of branches you have, such that: $2^{n}=2^{3}$ Before starting with the analysis, it is necessary to take into account the following considerations: 
Vol. 5, Issue 12, December 2016

- The analysis will be performed for the upper switches in each phase, since the lower switches are the complement of the first.

- For each switching state an equivalent circuit analysis will be performed to determine the voltages corresponding to each phase.

The eight possible switching states can be seen in Fig (4). It can be seen that two states do not produce any voltage, which would be states "000" and "111" Which are called "null states", while the rest of states are called "active states" [8].

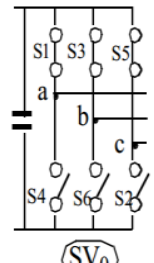

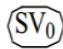

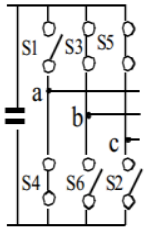

$\mathrm{SV}_{4}$

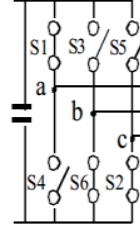

$\mathrm{SV}_{1}$

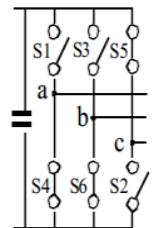

$\mathrm{SV}_{5}$

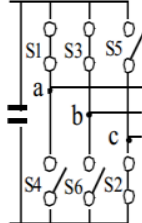

$\mathrm{SV}_{2}$

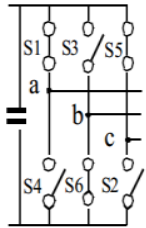

$\mathrm{SV}_{6}$

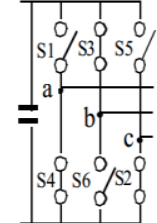

$\mathrm{SV}_{3}$

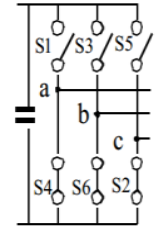

$\overparen{\mathrm{SV}_{7}}$
Fig. 4:Switching states of an inverter.

The phase voltages of the rest of the switching states can be easily calculated following the same procedure. The results are presented below in table 1

Table 1. Line and phase voltages of the different switching states.

\begin{tabular}{|c|c|c|c|c|c|c|c|c|c|}
\hline $\mathrm{S}_{\mathrm{A}}$ & $\mathrm{S}_{\mathrm{B}}$ & $\mathbf{S}_{\mathrm{C}}$ & $\mathrm{Vector}$ & $\mathrm{u}_{\mathrm{AB}}$ & $\mathrm{u}_{\mathrm{BC}}$ & $\mathrm{u}_{C A}$ & $\mathbf{u}_{\mathrm{A}}$ & $\mathbf{u}_{\mathrm{B}}$ & $\mathbf{u} \mathrm{c}$ \\
\hline 0 & 0 & 0 & $\mathrm{~V}_{000}$ & 0 & 0 & 0 & 0 & 0 & 0 \\
\hline 1 & 0 & 0 & $\mathrm{~V}_{0}$ & $u_{D C}$ & 0 & $-u_{D C}$ & $\frac{2 u_{D C}}{3}$ & $-\frac{u_{D C}}{3}$ & $-\frac{u_{D C}}{3}$ \\
\hline 1 & 1 & 0 & $\mathrm{~V}_{60}$ & 0 & $u_{D C}$ & $-u_{D C}$ & $\frac{u_{D C}}{3}$ & $\frac{u_{D C}}{3}$ & $-\frac{2 u_{D C}}{3}$ \\
\hline 0 & 1 & 0 & $\mathrm{~V}_{120}$ & $-u_{D C}$ & $u_{D C}$ & 0 & $-\frac{u_{D C}}{3}$ & $\frac{2 u_{D C}}{3}$ & $-\frac{u_{D C}}{3}$ \\
\hline 0 & 1 & 1 & $\mathrm{~V}_{180}$ & $-u_{D C}$ & 0 & $u_{D C}$ & $-\frac{2 u_{D C}}{3}$ & $\frac{u_{D C}}{3}$ & $\frac{u_{D C}}{3}$ \\
\hline 0 & 0 & 1 & $\mathrm{~V}_{240}$ & 0 & $-u_{D C}$ & $u_{D C}$ & $-\frac{u_{D C}}{3}$ & $-\frac{u_{D C}}{3}$ & $\frac{2 u_{D C}}{3}$ \\
\hline 1 & 0 & 1 & $\mathrm{~V}_{300}$ & $u_{D C}$ & $-u_{D C}$ & 0 & $\frac{u_{D C}}{3}$ & $-\frac{2 u_{D C}}{3}$ & $\frac{u_{D C}}{3}$ \\
\hline 1 & 1 & 1 & $\mathrm{~V}_{111}$ & 0 & 0 & 0 & 0 & 0 & 0 \\
\hline
\end{tabular}

As can be seen in Table 1, eight vectors are obtained for each possible switching state of the inverter, two of which are null vectors $(000$ and 111) and six are active vectors $(0,60,120,180,240$ and 300$)$. These vectors can be seen in Fig (5), and define six zones separated by 60 degrees, forming a hexagon [9].
As mentioned below, it is necessary to generate the reference vector from the basic vectors of the switching states, to do this we will perform the analysis of the vectors involved in each sector to determine the times in which they should be applied.The reference vector is known and reaches the SVPWM modulation decomposed into its components $\alpha$ and $\beta$, in addition also the magnitude and direction of the active vectors belonging to each section are known.

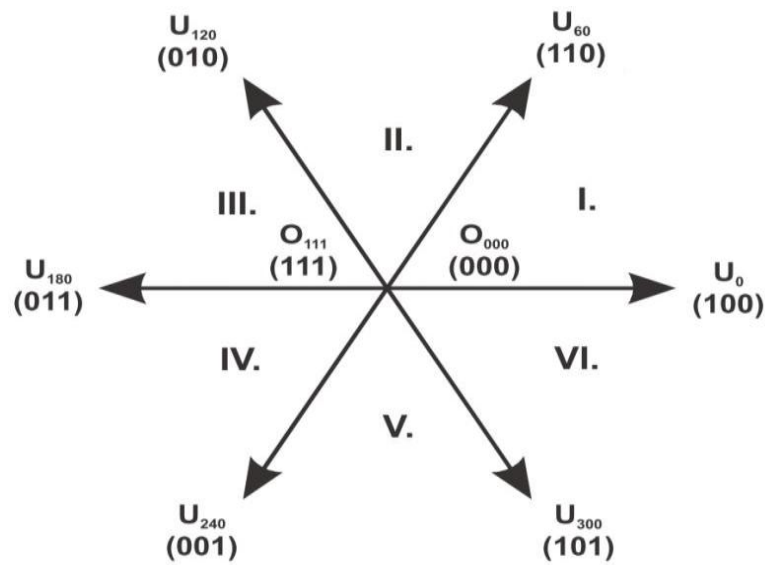

Fig. 5:Basic vectors of a two-level inverter.

The analysis will begin assuming that the reference vector is in sector 1. As can be seen in $\operatorname{Fig}(6)$, this sector is limited by the basic vectors V0 and V60, therefore the components of the reference vector US should be Decomposed in the components V0 and V60 in order to determine the duty cycle of these vectors and thus obtain the reference vector from the basic vectors involved.

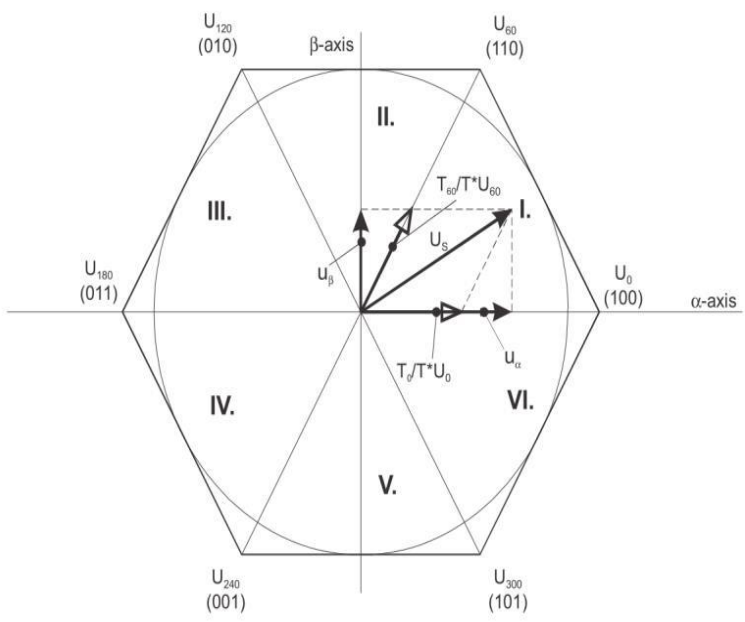

Fig. 6:Projection of the reference vector in sector 1

The principle of SVPWM modulation is to properly apply the switching states for a certain time, so that a voltage vector identical to the reference vector provided by the control algorithm can be generated [10]. Recalling Clark's transformation: 


$$
\left[\begin{array}{l}
\mathrm{U}_{\alpha} \\
\mathrm{U}_{\beta}
\end{array}\right]=\frac{2}{3}\left[\begin{array}{ccc}
1 & -\frac{1}{2} & -\frac{1}{2} \\
0 & \frac{\sqrt{3}}{2} & -\frac{\sqrt{3}}{2}
\end{array}\right]\left[\begin{array}{l}
\mathrm{u}_{\mathrm{A}} \\
\mathrm{u}_{\mathrm{B}} \\
\mathrm{u}_{\mathrm{C}}
\end{array}\right](25)
$$

\section{IV.SIMULATIONS OF THE MATHEMATICAL MODEL AND CONTROL}

The simulation stage is necessary in any process of implementation of new or different control techniques. At present there are different tools that give the possibility to perform all the necessary simulations before affecting the real system. The software used to perform the simulations in this work is MATLAB, all schemes were made in Simulink. This tool is frequently used for the modelling of electrical and mechanical systems, among others, for the simplicity it offers the user to implement different diagrams representing any system. Then the simulations corresponding to the IFOC control are presented. The block diagram that was implemented in Simulink to perform the IFOC control simulation is shown in Fig (7).

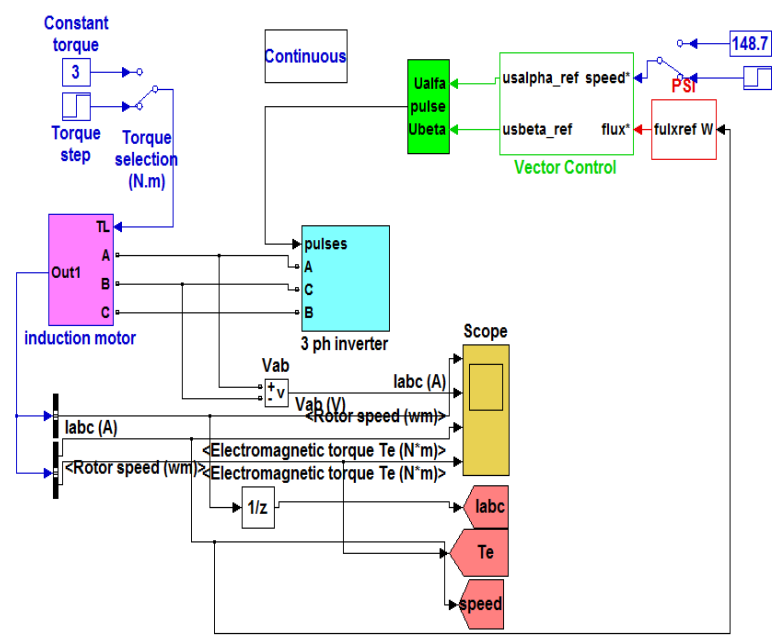

Fig. 7: Block diagram for IFOC control simulation.

In the IFOC control scheme there are basically four blocks without which control could not be performed. The first group of blocks corresponds to the PI controller. This variation of a PID controller is widely used in vector control. Another important block in the IFOC control algorithm is the one that calculates the magnetic flux of the rotor and its position. Finally, the SVPWM block is another important component of the IFOC control.

\section{RESULTS}

In this simulation it is desired to verify the response of the IFOC control to changes in the speed reference and load. Variations of up to $150[\mathrm{rad} / \mathrm{sec}]$ are made considering $118[\mathrm{rad} / \mathrm{sec}]$ as the operating point.

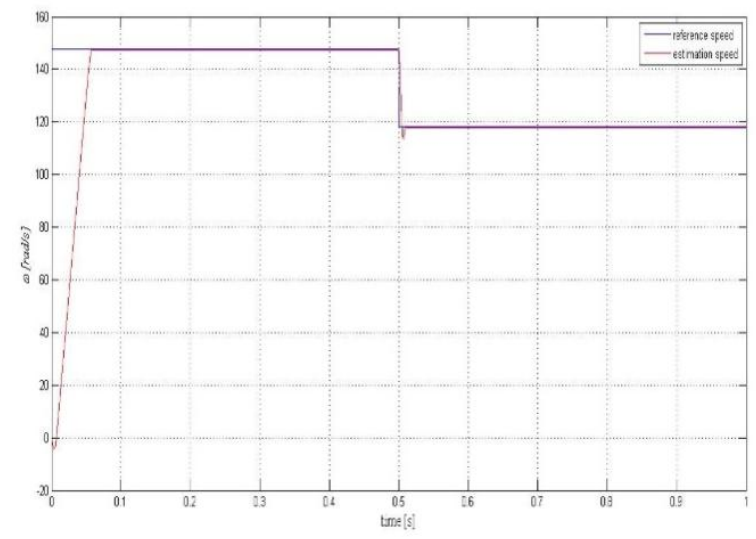

Fig. 8:IFOC control response to changes in speed. In Fig (8) it can be seen that the speed response of the motor reaches the reference. It also has a good response to the variations that were made (load and reference speed). It is interesting to see the behaviour of the currents with the variations of Speed. The following figures show the behaviour of the currents at different speed levels. It is worth mentioning that the current of a single phase and three phase will be graphed, in order not to recharge the graph and to have a better vision of its behaviour.

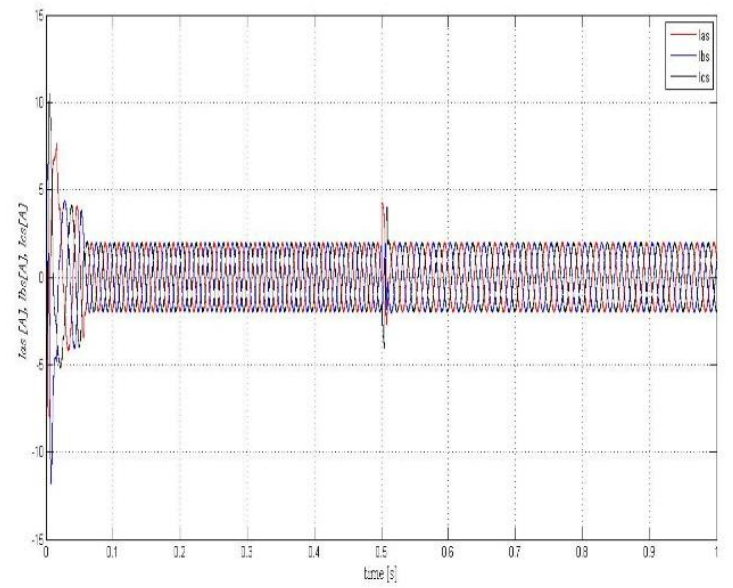

Fig. 9: Behaviour of 3-pcurrent with changes in speed.

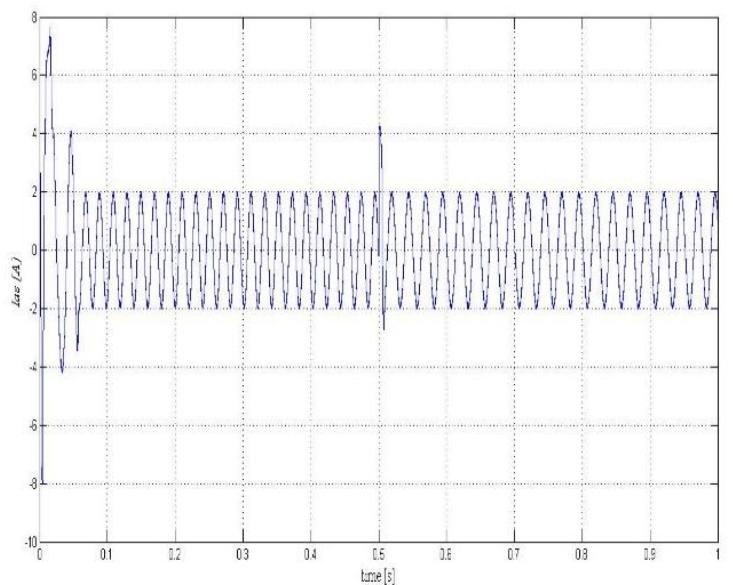

Fig.10: Behaviour of 1- $\varphi$ current with changes in speed. 
Vol. 5, Issue 12, December 2016

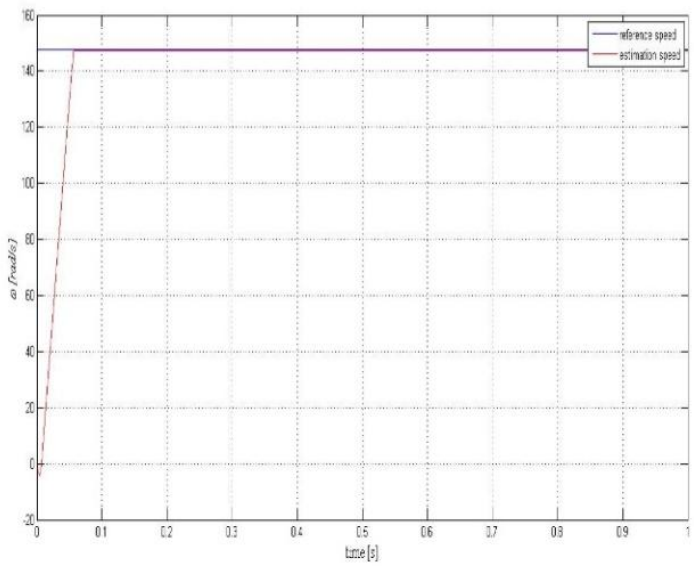

Fig. 11:IFOC control response to changes in speed. The current peak reaches approximately 4 times the current value in Steady state at $150[\mathrm{rad} / \mathrm{sec}]$. The shape of the current waveform of phase (A) and three phase for $150[\mathrm{rad} / \mathrm{sec}]$ with constant load. Is shown in Fig $(12,13)$.

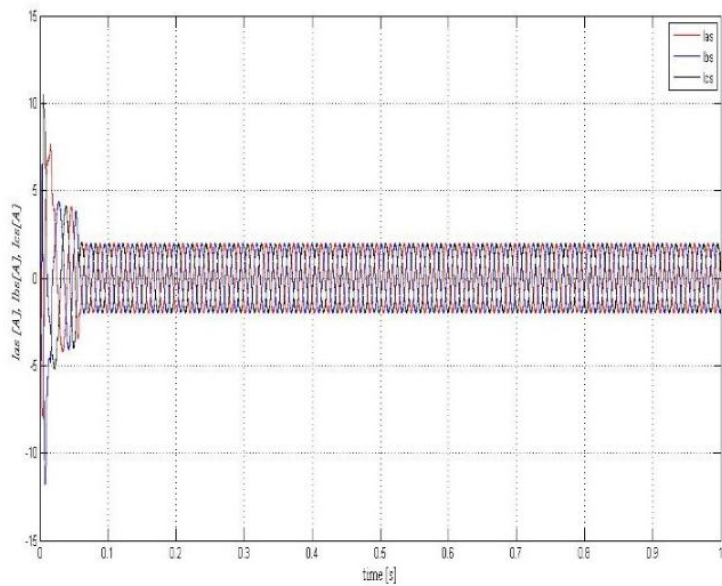

Fig. 12: Behaviour of 3-pcurrent with changes in speed.

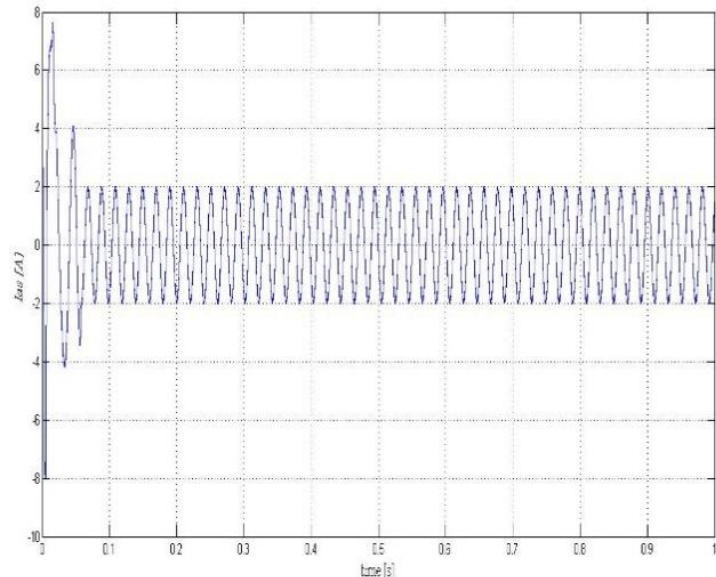

Fig. 13: Behaviour of 1-甲current with changes in speed.

Fig $(14,15,16)$ shows the current waveform for Variations of up to $150[\mathrm{rad} / \mathrm{sec}]$ are made considering $50[\mathrm{rad} / \mathrm{sec}]$ as the operating point at duration $0.5 \mathrm{sec}$.

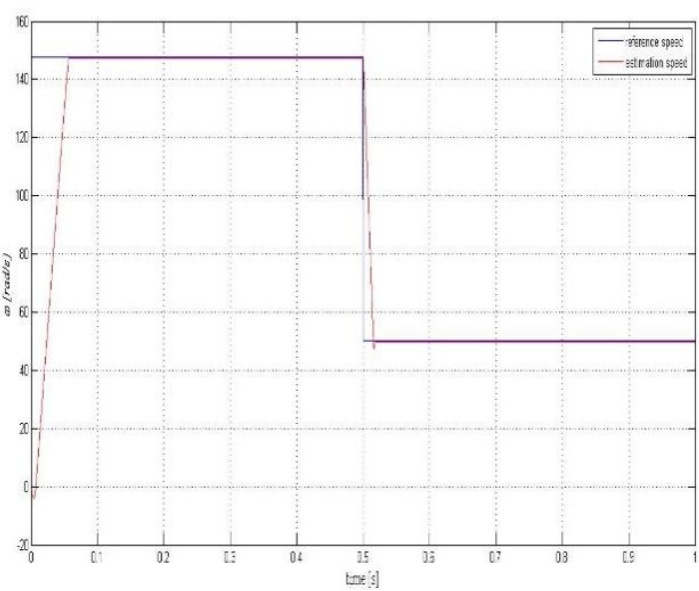

Fig. 14: IFOC control response to changes in speed.

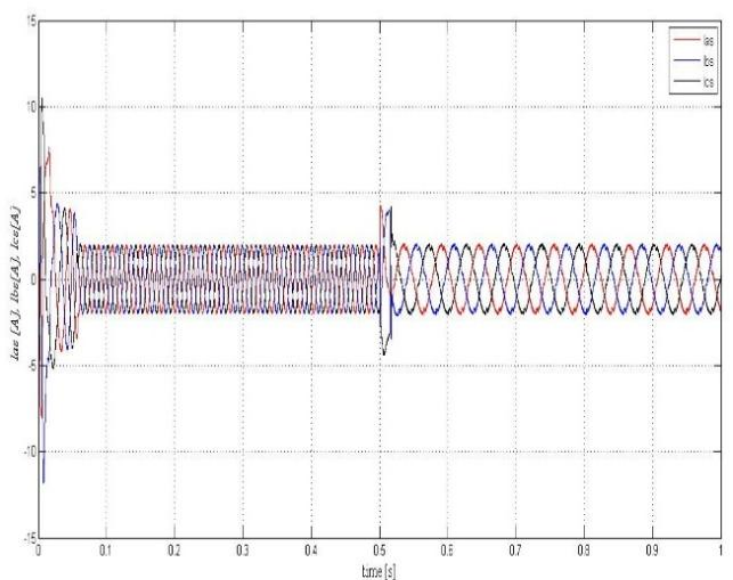

Fig. 15:Behaviour of 3- $\varphi$ current with changes in speed.

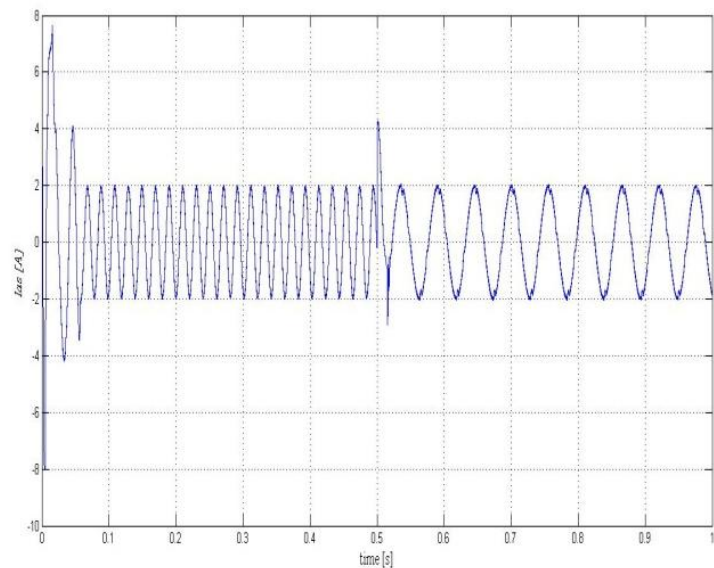

Fig.16:Behaviour of 1- $\varphi$ current with changes in speed.

Finally, Fig $(18,19)$ shows the current waveform for the multi- Variations of reference speed are made considering $(30,70,102,108,150)[\mathrm{rad} / \mathrm{sec}]$ as the operating point at multi-duration.

In the last three figures you can see the variations in the amplitude of the currents that are obtained when making variations to the speed reference and load. It can be deduced that the relation between amplitude and speed is inversely proportional. 


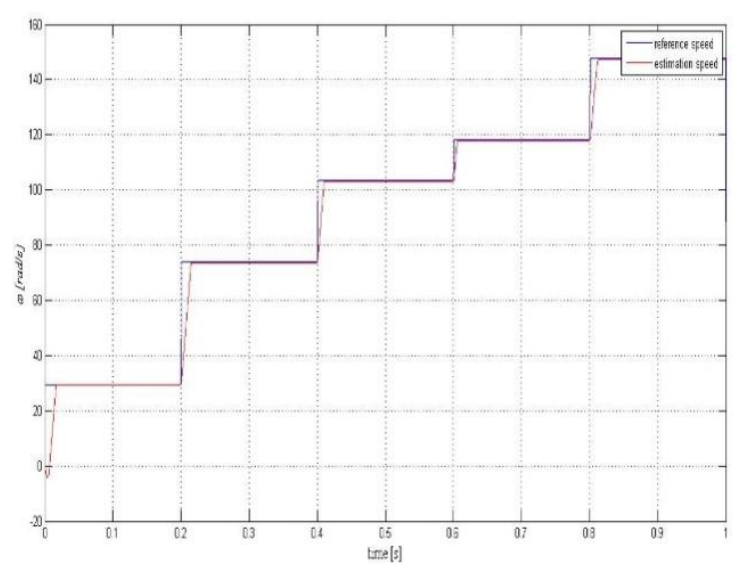

Fig. 17: IFOC control response to changes in speed

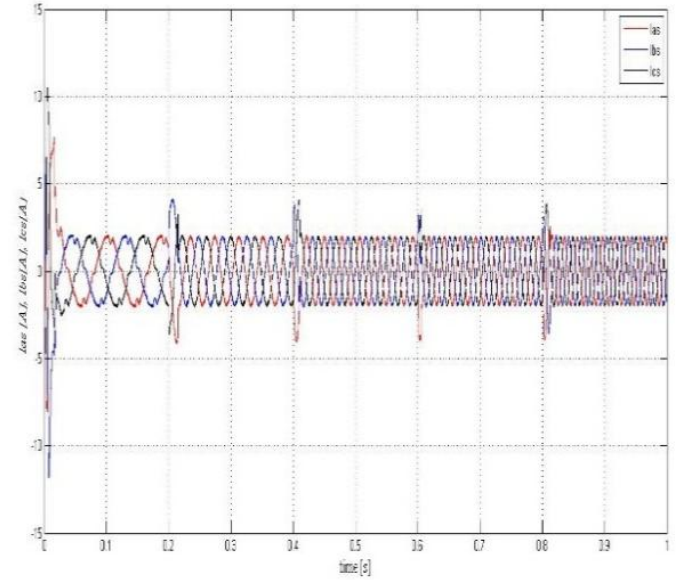

Fig. 18: Behaviour of 3-pcurrent with changes in speed.

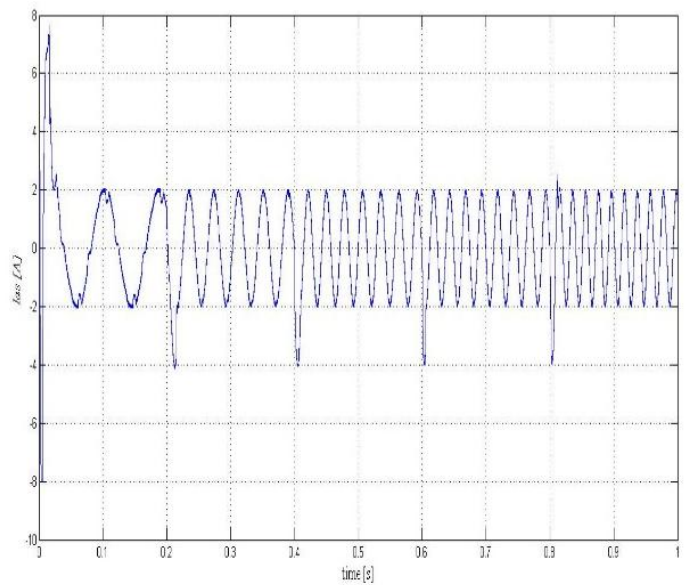

Fig. 19: Behaviour of 1- $\varphi$ current with changes in speed.

\section{VI.CONCLUSION}

The implementation of the IFOC advanced control method for a three-phase induction motor was successfully carried out. The control response to speed reference changes and its response to disturbances could be observed. In addition, the behaviour of the current was verified, and the variations of its frequency and its amplitude were observed in the different speed references that were established the speed control performed in this work is based on a point of operation, which is determined by the speed references and the current that are defined in the implemented IFOC control scheme. As shown, the variations of the speed reference have a determined magnitude and were performed around set point of operation. It was observed that by exceeding certain speed reference levels, the controller did not respond correctly, which is explained by the fact that the variations were only made in the speed reference but not in the reference.

\section{REFERENCES}

[1] K. Yang, Y. Choi, W. Chung" On the Tracking Performance Improvement of Optical Disk Drive Servo Systems using Errorbased Disturbance Observer, IEEE Transactions on Industrial Electronics, Vol. 52, No. 1, Feb. 2005, pp. $270-279$.

[2] W. Chen: Disturbance Observer based Control for Nonlinear Systems, IEEE/ASME Transaction on Mechatronics, Vol. 9, No. 4, Dec. 2004, pp. $706-710$.

[3] R. Krishnan, F. Doran"Study of Parameter Sensitivity in Highperformance Inverter-fed Induction Motor Drive Systems, IEEE Transaction on Industry Applications, Vol. 23, No. 4, July 1987, pp. $623-635$.

[4] I. Landau, A. Constantinescul, D. Rey"Adaptive Narrowband Disturbance Rejection Applied to an Active Suspension: An Internal Model Principle Approach, Automatica, Vol. 41, No. 4, April 2005, pp. $563-574$.

[5] D. W. Novotny and R. D. Lorenz, ed., "Introduction to Field Orientation and High Performance AC drives," Tutorial Course. IEEE-IAS Conf. Recd, Denver, 1986.

[6] E. Levi, S. Vukosavic, V. Vuckovic, "Study of main flux saturation in field oriented induction motor drives", Conf. Rec. IEEE Ind. Electron. Soc. Ann. Meet. IECON'89, pp 219-231.

[7] L. Garces, "Parameter Adaption for the Speed-Controlled Static AC Drive with a Squirrel-Cage Induction Motor", IEEE Trans. on Industry Application, vol.16, No 2, 1980, pp. 173-178.

[8] M. Mijalković, A. Stanković, S. Obradović, "Detuned operation of indirect field oriented control of induction motor" UNITECH07 Conf. Rec. Gabrovo, Bulgaria 2007.

[9] R. Swamy. and P. Kumar " Speed Control of Space Vector Modulated Inverter Driven Induction Motor. Proceedings of the International MultiConference of Engineers and Computer Scientists, 2008 Vol. 2.

[10] ]P. Alkorta, O. Barambones. and A. J. Garrido et al "SVPWM Variable Structure Control of Induction Motor Drives. Industrial Electronics ISIE, pp. 1195-1200, 2007.

[11] ]G. Esmaily, A. Khodabakhshian. and K. Jamshidi"Vector control of induction motors using UPWM Voltage source inverter", downloaded from www.itee.uq.edu.au on 4th March, 2010.

[12] Sheng-weiGao, You-Hua Wang, Yan Cai. and Chuang Zhang "Design and Simulation of Rotor Resistance Observer for Induction Motors Using Artificial Neural Network. International Conference on Measuring Technology and Mechatronics Automation, 2010.

\section{APPENDIX}

TABLE I. Parameters Which Used In Simulation for the Induction Motor 
International Journal of Advanced Research in Computer and Communication Engineering ISO 3297:2007 Certified

Vol. 5, Issue 12, December 2016

\begin{tabular}{|ll|}
\hline Stator Resistance $=11.6$ & {$[\mathrm{Ohm}]$} \\
\hline Rotor Resistance=10.4 & {$[\mathrm{Ohm}]$} \\
\hline Stator Inductivity $=0.579$ & {$[\mathrm{H}]$} \\
\hline Rotor Inductivity $=0.579$ & {$[\mathrm{H}]$} \\
\hline Mutual Inductivity $=0.557$ & {$[\mathrm{H}]$} \\
\hline Inertia $=0.002$ & {$[\mathrm{kgm} \wedge$} \\
\hline Nominal Frequency $=50$ & {$[\mathrm{~Hz}]$} \\
\hline Nominal Power=750 & {$[\mathrm{W}]$} \\
\hline Nominal Speed=1410 & {$[\mathrm{rmm}]$} \\
\hline Nominal Phase Voltage=220 & {$[\mathrm{V}]$} \\
\hline N0. POLES $=2$ & \\
\hline
\end{tabular}

